\title{
Benzene-Derived $N^{2}$-(4-Hydroxyphenyl)-Deoxyguanosine Adduct: UvrABC Incision and Its Conformation in DNA
}

\author{
Ben Rodriguez ${ }^{2}$, Yanu Yang ${ }^{2}$, Anton B. Guliaev ${ }^{2}$, Ahmed Chenna $^{3}$, and Bo Hang ${ }^{1 *}$ \\ ${ }^{1}$ Department of Cancer and DNA Damage Responses, \\ Life Sciences Division, Lawrence Berkeley National Laboratory, \\ Berkeley, CA 94720, United States \\ ${ }^{2}$ Department of Chemistry and Biochemistry, \\ San Francisco State University, \\ San Francisco, CA 94132, United States \\ ${ }^{3}$ Monogram Biosciences Inc., \\ South San Francisco, CA 94080, United States \\ *Corresponding author: Tel: (510) 495-2537, Fax: (510) 486-6488 \\ E-mail: Bo_hang@lbl.gov
}

\section{Running title:}

Conformation and UvrABC Incision of $N^{2}-4-\mathrm{HOPh}-\mathrm{dG}$ 


\begin{abstract}
Abbreviations:
HQ, hydroquinone; $p$-BQ, $p$-benzoquinone; $N^{2}$-4-HOPh-dG, $N^{2}$-(4-hydroxyphenyl)2'-deoxyguanosine; AP, apurinic/apyrimidinic; UvrABC, E. coli UvrABC complex; NER, nucleotide excision repair; BER, base excision repair; Exo III, Exonuclease III; Endo IV, endonuclease IV; APE1, human AP endonuclease 1; MD, molecular dynamics.
\end{abstract}




\begin{abstract}
Benzene, a ubiquitous human carcinogen, forms DNA adducts through its metabolites such as $p$-benzoquinone ( $p$-BQ) and hydroquinone (HQ). $N^{2}$-(4-Hydroxyphenyl)-2'deoxyguanosine $\left(N^{2}-4-\mathrm{HOPh}-\mathrm{dG}\right)$ is the principal adduct identified in vivo by ${ }^{32} \mathrm{P}-$ postlabeling in cells or animals treated with $p$-BQ or HQ. To study its effect on repair specificity and replication fidelity, we recently synthesized defined oligonucleotides containing a site-specific adduct using phosphoramidite chemistry. We here report the repair of this adduct by Escherichia coli UvrABC complex, which performs the initial damage recognition and incision steps in the nucleotide excision repair (NER) pathway. We first showed that the $p$-BQ-treated plasmid was efficiently cleaved by the complex, indicating the formation of DNA lesions that are substrates for NER. Using a 40-mer substrate, we found that UvrABC incises the DNA strand containing $N^{2}-4-\mathrm{HOPh}-\mathrm{dG}$ in a dose- and time-dependent manner. The specificity of such repair was also compared with that of DNA glycosylases and damage-specific endonucleases of E. coli, both of which were found to have no detectable activity toward $N^{2}-4-\mathrm{HOPh}-\mathrm{dG}$. To understand why this adduct is specifically recognized and processed by UvrABC, molecular modeling studies were performed. Analysis of molecular dynamics trajectories showed that stable G:C-like hydrogen-bonding patterns of all three Watson-Crick hydrogen bonds are present within the $N^{2}-4-\mathrm{HOPh}-\mathrm{G}: \mathrm{C}$ base pair, with the hydroxyphenyl ring at an almost planar position. In addition, $N^{2}-4-\mathrm{HOPh}-\mathrm{dG}$ has a tendency to form more stable stacking interactions than a normal G in B-type DNA. These conformational properties may be critical in differential recognition of this adduct by specific repair enzymes.
\end{abstract}


Keywords: Benzene; hydroquinone; $p$-benzoquinone; DNA adduct; UvrABC, Nucleotide excision repair; adduct conformation, molecular modeling 


\section{Introduction}

Benzene is a common environmental pollutant with wide usage in industry (Wallace, 1996). Human exposure to benzene comes from gasoline and automobile combustion products, and from certain industries such as oil refineries and petrochemical/rubber manufacturing (IARC, 1982; NTP, 2005). Cigarette smoking is another major source as it is estimated to account for about half of the entire nationwide exposure to benzene (Wallace, 1996). Benzene is classified as a human carcinogen by the International Agency for Research on Cancer (IARC) and National Toxicology Program (NTP) (IARC, 1982; NTP, 2005). In rodents, benzene exposure has been demonstrated to cause tumors at multiple organ sites (Huff et al., 1989). Several human epidemiological studies (e.g., Sorahan et al., 2005; Yin et al., 1996) have revealed a relationship between occupational benzene exposure and an increased incidence of leukemia, primarily acute myeloid leukemia. An increased risk of breast and lung cancer among benzene exposed populations has also been suggested from limited epidemiological or population-based studies (Costantini et al., 2009; Hansen, 2000; Petralia et al., 1999; Yin et al., 1996).

Benzene must be metabolized to more reactive compounds to exert its effects. Despite extensive investigation of the biological effects of benzene and its major metabolites for many years, the precise mechanisms underlying benzene mutagenicity and carcinogenicity remain unclear. Nevertheless, several possible mechanisms have been proposed with focuses on interactions of benzene with different cellular components as well as resulting structural and biological impacts. One of the mechanisms concerns the formation of mutagenic DNA damage by benzene 
metabolites in certain types of target cells/tissues, particularly the hematopoietic progenitor cells in the bone marrow (McDonald et al., 2001; Whysner et al., 2004). DNA adducts have been detected in these cells or tissues following exposure to benzene or its metabolites (Whysner et al., 2004). The role of DNA adduct formation is also supported by the evidence from induced mutagenesis following transfection of $p$-benzoquinone ( $p$-BQ)- or hydroquinone (HQ)-damaged shuttle vectors into cultured mammalian cells (Gaskell et al., 2004, 2005; Nakayama et al., 2004).

A major class of DNA adducts found to be formed in vitro by $p$-BQ or HQ are the exocyclic benzetheno adducts of dG, dA and dC (Gaskell et al., 2002; Jowa et al., 1986; Pongracz and Bodell, 1991; Pongracz et al., 1990). To study their biochemical and biological properties, we previously synthesized oligonucleotides containing these adducts at a single location (Chenna and Singer, 1995, 1997). Our site-directed mutagenesis experiments showed that these adducts are highly mutagenic in the cell (Xie et al., 2005). We have also demonstrated that all three benzetheno adducts are substrates for exonuclease III (Exo III) and endonuclease IV (Endo IV) of E. coli and the major apurinic/apyrimidinic (AP) endonuclease (APE1) of humans (Chenna et al., 1995; Guliaev et al., 2004; Hang et al., 1996; Hang et al., 1998). These enzymes hydrolyze the phosphodiester bond immediate 5 ' to the adduct, leaving the benzetheno derivative on the 5 '-terminal of the 3 ' fragment as a "dangling base" (Hang et al., 1996), a mechanism which was later referred as nucleotide incision repair (NIR) (Ischenko and Saparbaev, 2002).

Benzene-derived DNA adducts have also been reported in certain tissues or cultured cells after exposure. By ${ }^{32} \mathrm{P}$-postlabeling, Bauer et al showed the formation 
of DNA adducts in liver of rabbits treated with benzene (Bauer et al., 1989). Bodell and co-workers later detected several adducts in human promyelocytic leukemia HL60 cells (Levay et al., 1991; Pongracz and Bodell, 1996) and in the bone marrow cells of mice (Bodell et al., 1996) treated with benzene, $p$-BQ or HQ. The principal adduct detected in these cells/tissues by ${ }^{32} \mathrm{P}$-postlabeling corresponded to $N^{2}-4-\mathrm{HOPh}$ dG-3'-phosphate (Levay et al., 1991; Pongracz and Bodell, 1996) (see Figure 1 for adduct structure). The same adduct could be identified in vitro by allowing guanosine 3'-phosphate to react with $p$-BQ (Levay et al., 1991; Pongracz and Bodell, 1996). To date, to the best of our knowledge, both biochemical and biological properties of this adduct have not been studied. In light of the observation that induction of benzene toxicity in the bone marrow correlates with the adduct formation (Bodell et al., 1996) and that induced mutagenesis studies suggest a major role of the $p$-BQ- or HQinduced dG adducts in benzene mutagenesis (Gaskell et al., 2004, 2005; Nakayama et al., 2004), it was of great interest for us to investigate the repair of $N^{2}-4-\mathrm{HOPh}-\mathrm{dG}$ by cellular repair mechanisms.

Based on the chemical structure of $N^{2}-4-\mathrm{HOPh}-\mathrm{dG}$ and known substrate specificity of respective repair pathways, we examined the specificity toward this adduct of enzymes from three different $E$. coli repair mechanisms, all of which have been well characterized and are highly conserved from bacteria to mammalian cells. Such work was greatly facilitated by our ability to synthesize the defined DNA oligonucleotides containing $N^{2}-4-\mathrm{HOPh}-\mathrm{dG}$ at a specific position (Chenna et al., 2008). As stated above, AP endonucleases Exo III and Endo IV are able to recognize and repair benzene-derived benzetheno adducts which have gained two extra rings on 
the nucleotide base. While the BER pathway primarily targets relatively small base modifications such as alkylated and oxidized bases, it is able to repair certain 5- or 6membered exocyclic ring adducts, as shown by us and others (Hang, 2004). The NER pathway is the major mechanism for repair of bulky DNA adducts of various chemical structures (Friedberg et al., 2005; Reardon and Sancar, 2005), which was expected by us to be the primary mechanism for repair of $N^{2}-4-\mathrm{HOPh}-\mathrm{dG}$ adduct. In E. coli, the initial steps of NER are carried out by the UvrABC proteins, which perform at least two sequential reactions. First, UvrA and UvrB are involved in recognition of chemical modification and structural distortion in duplex DNA, leading to the formation of the UvrB-DNA complex; Second, UvrC is recruited to the damaged site and makes incisions on the sides of the damage.

In this study, the results showed that $N^{2}-4-\mathrm{HOPh}-\mathrm{dG}$ is specifically recognized and processed by the UvrABC complex, but not by the glycosylases and AP endonucleases tested. To gain a structural rationale for this novel substrate specificity, molecular dynamics (MD) simulations were performed to analyze the effect of $N^{2}-4$ HOPh-dG on local conformation of the DNA duplex. The significance and implications of these findings were discussed.

\section{Materials and Methods}

\subsection{DNA substrates and repair proteins}

The synthesis of the 5'-DMT-3'-phosphoramidite of $N^{2}-4-\mathrm{HOPh}-\mathrm{dG}$ and its sitespecific incorporation into defined oligonucleotides were previously described by Chenna et al. (Chenna et al., 2008). The unmodified controls, complementary strands 
and DNA size markers were purchased from Operon Inc. (Alameda, CA). All oligomers were HPLC- and/or PAGE-purified before assayed (see Figs 3 and 5 for sequences used in this study).

To generate plasmid globally modified by $p$-BQ, pCMV vector (Invitrogen) (15 $\mu \mathrm{g}$ ) was treated with several concentrations of $p$-BQ (Sigma, St. Louis, MO, stock: $500 \mathrm{mg} / \mathrm{ml}$ in methanol) or methanol only in $80 \mu \mathrm{l}$ at $37^{\circ} \mathrm{C}$ overnight. Both $p$-BQtreated and untreated plasmids were purified using the QIAprep Spin Miniprep Kit (Qiagen, Valencia, CA) and dissolved in TE buffer ( $\mathrm{pH} 8.0)$.

Purified recombinant UvrA, UvrB and UvrC proteins were purchased from BD Biosciences (San Jose, CA). These subunits were purified from E. coli DR153 overexpressing the uvrA, uvrB and uvrC genes, respectively. Exo III was purchased from Gibco BRL (Carlsbad, CA). Endo IV was from R\&D Systems (Minneapolis, $\mathrm{MN}$ ). Mismatch uracil-DNA glycosylase (Mug), endonuclease III (Nfo), endonucleae VIII (Endo VIII), formamidopyrimidine-DNA glycosylase (Fpg), and MutY were all purchased from Trevigen (Gaithersburg, MD).

\subsection{Incision assays}

UvrABC incision of $p$-BQ-modified plasmid DNA was measured at $30^{\circ} \mathrm{C}$ with varying UvrABC concentrations or times in a total volume of $50 \mu \mathrm{l}$. The UvrABC subunits were diluted with a dilution buffer and premixed prior to the reaction. The reactions were carried out using $0.75 \mu \mathrm{g}$ plasmid DNA in a UvrABC buffer containing $50 \mathrm{mM}$ Tris- $\mathrm{HCl}$ (pH 7.5), $50 \mathrm{mM} \mathrm{KCl}, 10 \mathrm{mM} \mathrm{MgCl} 2,0.1 \mathrm{mg} / \mathrm{ml} \mathrm{BSA}, 5 \mathrm{mM}$ DTT and $2 \mathrm{mM}$ ATP. All reactions, after terminated with $25 \mathrm{mM}$ EDTA, were resolved on a 
$1 \%$ agarose gel with $0.3 \mu \mathrm{g} / \mathrm{ml}$ ethidium bromide and visualized with an IS-500 Digital Imaging System (Alpha Innotech). DNA nicking was determined by the conversion of supercoiled plasmid into the linear form.

To test for UvrABC activity toward $N^{2}-4-\mathrm{HOPh}-\mathrm{dG}$, both adduct-containing and unmodified 40-mers were 5'-terminally labeled with $\left[\gamma_{-}{ }^{32} \mathrm{P}\right]$ ATP (specific activity 6,000 Ci/mmol; $1 \mathrm{Ci}=37 \mathrm{GBq}$, Perkin Elmer, Boston, MA) and annealed to a complementary strand in a buffer containing 10 mM HEPES-KOH (pH 7.5) and 100 $\mathrm{mM} \mathrm{NaCl}$. The reaction mixtures contained $2 \mathrm{nM}$ radiolabeled DNA substrate in a UvrABC buffer containing $50 \mathrm{mM}$ Tris- $\mathrm{HCl}\left(\mathrm{pH}\right.$ 7.5), $50 \mathrm{mM} \mathrm{KCl,} 10 \mathrm{mM} \mathrm{MgCl}_{2}, 0.1$ $\mathrm{mg} / \mathrm{ml} \mathrm{BSA,} 5 \mathrm{mM}$ DTT, 2mM ATP, and varying amounts of UvrABC subunits as indicated in the figures. The reactions were terminated by adding an equal volume of F/E solution ( $90 \%$ formamide, $50 \mathrm{mM}$ EDTA, and 0.2\% bromophenol blue) followed by heating at $95-100{ }^{\circ} \mathrm{C}$ for $5 \mathrm{~min}$. The reaction products were resolved on a $12 \%$ denaturing PAGE and the radioactivity was scanned with a Molecular Imager FX (BioRad, Hercules, CA). For quantification of radioactivity of the bands, Quantity One software (version 4.0.1) was used.

The incision assay used to examine potential endonuclease activity of Exo III and Endo IV toward $N^{2}-4-\mathrm{HOPh}-\mathrm{dG}$ was carried out as described by Hang et al. (Hang et al., 1998). The reactions were performed with varying amounts of enzyme at $37^{\circ} \mathrm{C}$ in a total volume of $10 \mu \mathrm{l}$ in $10 \mathrm{mM}$ HEPES-KOH, $\mathrm{pH}$ 7.4, $100 \mathrm{mM} \mathrm{KCl}$ and $1 \mathrm{mM}$ DTT. The reactions were terminated and electrophoresed as described above.

\subsection{DNA glycosylase assays}


The enzymatic assay used to test glycosylase-catalyzed excision of $N^{2}-4-\mathrm{HOPh}-$ dG from a 25-mer oligonucleotide was carried out essentially as previously described (Hang et al., 2002). Briefly, the reactions were performed with a purified glycosylase in a $10 \mu \mathrm{l}$ volume for $1 \mathrm{~h}$ at $37^{\circ} \mathrm{C}$ in a corresponding glycosylase buffer. For further cleavage of potential AP sites formed by the action of a glycosylase, an alkaline buffer $(5 \mu \mathrm{l})$ containing $300 \mathrm{mM} \mathrm{NaOH}, 97 \%$ formamide and $0.2 \%$ bromophenol blue was added to the reactions, which were then heated at $95-100^{\circ} \mathrm{C}$ for $5 \mathrm{~min}$ and resolved by $12 \%$ denaturing PAGE.

\subsection{Molecular dynamics (MD) simulations}

MD simulations were performed using the AMBER 9.0 modeling package with Cornell et al. force field and the parm99.dat parameter set. A model of unmodified 25-mer was built in a standard B-DNA conformation. The $N^{2}-4-\mathrm{HOPh}-\mathrm{G}$ adduct was placed opposite $\mathrm{C}$ in the $7^{\text {th }}$ position of the 25 -mer duplex (see Fig. 5 for sequence). The force field parameters for this adduct were developed consistent with the AMBER force field. A geometry optimized coordinates for $N^{2}-4-\mathrm{HOPh}-\mathrm{dG}$ was obtained with ab initio Hartree-Fock calculations with the 6-31G* basis set using PC GAMESS 7.1 (Schmidt et al., 1993). The force constants for bonds and angles were assigned by analogy with chemically similar atom types in the AMBER force field. The partial charges for the modified nucleotide were fit with the RESP module of AMBER (Bayly et al., 1993) using RED III (Pigache et al., 2004). The equilibration and production runs were performed based on a previously described procedure (Guliaev et al., 2002, 2004). All calculations used periodic boundary conditions with 
explicit solvent. The constructed 25 -mer duplex was solvated in a truncated octahedral box of TIP3P water molecules. The Coulombic interactions were calculated with the particle-mesh Ewald method using 1 A charge grid spacing with B-spline interpolation and a sum tolerance of $10^{-6} \AA$. A cutoff of $12 \AA$ was applied to Lennard-Jones interactions and SHAKE algorithm was used for all X-H bonds with the 2 femtosecond (fs) time step. Overall, 12.5 nanosecond (ns) MD simulations were carried for the 25-mer DNA duplex containing $N^{2}-4-\mathrm{HOPh}-\mathrm{G}_{7}: \mathrm{C}_{44}$ pair and the corresponding unmodified duplex. The stability of the MD simulation was evaluated based on rsmd values for each snapshot in the trajectory relative to its initial structure. Structures generally fluctuate stably after $1.0 \mathrm{~ns}$ and the last $12 \mathrm{~ns}$ were used for the conformational analysis.

Coordinates, velocities, and energies for each simulation were collected every 0.4 picosecond (ps). Each trajectory was analyzed and processed using PTRAJ and ANAL modules of the AMBER suite. For hydrogen bond analysis, the percent occupancy was calculated based on a heavy atom-heavy atom distance cutoff of $\leq 3.3$ $\AA$ and a heavy atom-hydrogen-heavy atom angle of $\leq 130^{\circ}$. The stacking interactions were estimated by computing the van der Waals interactions energies between adjacent bases, including the modified $\mathrm{G}$ and the opposite $\mathrm{C}$. All calculations were performed on a 16 core Linux cluster.

\section{Results}

\subsection{UvrABC incision of p-BQ-treated plasmid DNA}


To determine whether $p$-BQ globally modified DNA contains lesions that are substrates for NER, plasmid pCMV was treated with $p$-BQ and then incubated with the assembled UvrABC complex. We observed that, under an excess of UvrABC, the percentage of incised plasmid (from supercoiled to open circular form) correlated with the $p$-BQ concentrations used (from 0 to $80 \mathrm{mg} / \mathrm{ml}$ ) (data not shown). Based on the extent of incision and the level of background cutting, the plasmid DNA treated with $20 \mathrm{mg} / \mathrm{ml}$ of $p$-BQ was used for subsequent reactions shown in Fig. 2, in which UvrABC incised the $p$-BQ-modified plasmid DNA in a protein-dependent manner. Although the unmodified plasmid DNA exhibited low levels of non-specific cutting with increasing amounts of UvrABC, the modified plasmid DNA was efficiently incised by the nuclease, reaching almost $100 \%$ completion at the highest protein concentration used (Fig. 2, top right panel). Although the exact nature of the DNA lesion(s) incised by UvrABC is unknown in using this type of assay, these results suggest the involvement of NER in the repair of $p$-BQ-derived DNA damage, primary or secondary.

\subsection{UvrABC incision of the oligonucleotide containing $N^{2}-4-H O P h-d G$}

The UvrABC complex was further tested for its activity toward a single adduct $N^{2}$ 4-HOPh-dG in DNA using an incision assay. As shown in Fig. 3 top, the 40-mer duplex substrate contained the adduct in the middle of the top strand (20th position) which was 5' end-labeled with ${ }^{32} \mathrm{P}$. The representative gel image in Fig. 3 demonstrates that $\mathrm{Uvr} A B C$ was capable of incising this adduct-containing substrate, with the major incision made at the $8^{\text {th }}$ phosphodiester bond $5^{\prime}$ to the adduct, as 
indicated by the 12-mer marker. Such an incision pattern (site) is in agreement with those reported earlier for other DNA lesions (Reardon and Sancar, 2005). In lane 4 of Fig. 3, several minor incisions were also observed on the 5' side of the major incision, which are further away from the adduct. Similar 5' extra cuts by UvrABC have also been described previously for other DNA adducts (Moolenaar et al., 1998; Zou et al., 2003). No specific incision(s) was detected for the unmodified 40-mer under the same UvrABC concentration used (Fig. 3, lane 2). Further characterization of kinetics of UvrABC incision against $N^{2}-4-\mathrm{HOPh}-\mathrm{dG}$ is shown in Fig. 4. An initial rate of UvrABC incision can be demonstrated by a near linear increase in the total amount of both the major and extra incision products during the 30 min reaction time. These results clearly indicate that $N^{2}-4-\mathrm{HOPh}-\mathrm{dG}$ is specifically recognized and repaired by the UvrABC-mediated NER pathway.

We previously reported that certain AP endonucleases, including E. coli Exo III and Endo IV and human APE1, are able to incise $p$-BQ-derived benzetheno adducts at the 5' phosphodiester bond adjacent to the adduct (Hang et al., 1996; Hang et al., 1998). Using the same in vitro assay, we tested these enzymes for their potential activity for $N^{2}-4-H O P h-d G$. There was no specific incision of the adduct-containing 40-mer observed when Exo III and Endo IV were tested in this study (data not shown).

We also examined whether BER might be involved in the removal of this adduct. A 25-mer oligomer substrate containing $N^{2}-4-\mathrm{HOPh}-\mathrm{dG}$ at $7^{\text {th }}$ position (Fig. 5 top) was used to react with a battery of available DNA glycosylases from E. coli. The reasons for using a 25 -mer substrate were that, unlike the 40-mer substrate described above, the 25-mer was not incised by UvrABC due to its short size; the same 25-mer sequence but 
with different adducts located in it has been used successfully for studying BER in our past research. It has been shown that alkylated bases as well as certain 5- and 6membered exocyclic adducts are excised by specific DNA glycosylases. In E. coli, these enzymes are primarily the AlkA and Mug proteins (Hang, 2004; Singer and Hang, 1997). Here we did not detect any significant excision of $N^{2}-4-H O P h-G$ by the glycosylases tested in Fig. 5, under the assay conditions utilized previously for their primary known substrates.

\subsection{Conformation of DNA containing a $N^{2}-4-H O P h-d G$ adduct}

To analyze the impact of $N^{2}-4-\mathrm{HOPh}-\mathrm{dG}$ on local DNA conformation, MD simulations using the AMBER 9.0 modeling package with the Cornell et al. force field were performed. The simulation stability for the $N^{2}-4-\mathrm{HOPh}-\mathrm{G}_{7}: \mathrm{C}_{44}$ paircontaining DNA duplex was evaluated by calculating rmsd values for each $0.4 \mathrm{ps}$ relative to the starting structure. The system reached conformational equilibrium after $800 \mathrm{ps}$ and the representative conformation was calculated by averaging the last 11.5 ns of the $12.5 \mathrm{~ns}$ MD simulation. $N^{2}-4-\mathrm{HOPh}-\mathrm{G}_{7}$ and $\mathrm{C}_{44}$ formed a stable base pair with the hydroxyphenyl (HOPh) substituent being located in the minor groove of the DNA. The overall conformation of the adduct-containing base pair was similar to that of the unmodified G:C pair and was stabilized by the three Watson-Crick hydrogen bonds $N^{2}-4-\mathrm{HOPh}-\mathrm{G}_{7} \mathrm{~N} 2---\mathrm{C}_{44} \mathrm{O} 2, N^{2}-4-\mathrm{HOPh}-\mathrm{G}_{7} \mathrm{~N} 1---\mathrm{C}_{44} \mathrm{~N} 3$ and $N^{2}-4-\mathrm{HOPh}-\mathrm{G}_{7} \mathrm{O} 6-$ $--\mathrm{C}_{44} \mathrm{~N} 4$, which were occupied $95.3,95.5$ and $94.3 \%$, respectively, during the entire

course of simulation (Table 1). The hydrogen bonding criteria were $3.3 \AA$ distance between heavy atoms with the hydrogen bonding angle for donor-hydrogen-acceptor of $130^{\circ}$. 
The top and side views of the three base pair motifs, $\mathrm{A}_{6}-N^{2}-4-\mathrm{HOPh}-\mathrm{G}_{7}-\mathrm{C}_{8} / \mathrm{T}_{45^{-}}$ $\mathrm{C}_{44}-\mathrm{G}_{43}$, and the corresponding control, are shown in Fig. 6. The dynamic analysis of

the $N^{2}-4-\mathrm{HOPh}-\mathrm{dG}$ torsion angles between the $\mathrm{HOPh}$ substituent and the guanine base, i.e., $\alpha \mathrm{N} 1-\mathrm{C} 2-\mathrm{N}^{2}-\mathrm{C} 6(\mathrm{HOPh})$ and $\beta \mathrm{C} 2-\mathrm{N}^{2}-\mathrm{C} 6(\mathrm{HOPh})-\mathrm{C} 5(\mathrm{HOPh})$, showed certain conformational flexibility with the overall distribution between $50^{\circ}$ and $-50^{\circ}$. The mean values and standard deviations (in parenthesis) are $-4.6^{\circ}\left(11^{\circ}\right)$ and $-4.6^{\circ}$ $\left(14^{\circ}\right)$ for $\alpha$ and $\beta$, respectively. Thus, the average structure obtained from the MD simulation showed an almost planar position of the HOPh ring (bottom part of Fig. 6). No hydrogen bonding interactions were observed between the hydroxyl group of $\mathrm{HOPh}$ and the neighboring bases.

The van der Waals interaction energies computed over MD trajectory showed that the stacking interactions at the lesion site are approximately $3 \mathrm{kcal} / \mathrm{mol}$ lower than those at the corresponding site in the unmodified duplex (Fig. 7). The ability to generate more stable stacking interactions between the adducted $\mathrm{G}$ and its adjacent bases can be attributed to additional stacking contributions from the $\mathrm{HOPh}$ ring.

\section{Discussion}

One critical mechanism in prevention of mutagenic carcinogen-induced genotoxicity is to remove modified bases from the genomic DNA. Benzene and its major metabolites, such as $p$-BQ and HQ, have been shown to have the ability to modify DNA bases both chemically and in animal experiments. Our earlier work on $p$ BQ-induced benzetheno adducts has yielded valuable information as to their repair (Guliaev et al., 2004; Hang et al., 1996; Hang et al., 1997; Rothwell et al., 2000), 
mutagenic potential (Xie et al., 2005), and structure-function relationships involved in these processes. However, for the in vivo adduct formed by $p$-BQ or HQ, $N^{2}-4-\mathrm{HOPh}-$ $\mathrm{dG}$, neither its role in mutagenesis nor its repair has been revealed thus far. Given that guanine mutations are most commonly found in benzene-induced mutagenesis and that $N^{2}-4-\mathrm{HOPh}-\mathrm{dG}$ is the major adduct formed in vivo by $p-\mathrm{BQ} / \mathrm{HQ}$, it is of importance to understand how such an adduct is dealt with by cellular processes and whether any repair mechanism is important for benzene-induced mutagenesis. In recent years, other mechanisms underlying benzene carcinogenicity have also been proposed, particularly in two areas (McDonald et al., 2001; Whysner et al., 2004). First, benzene-induced ROS formation gives rise to oxidative DNA damage and altered signaling pathways. Second, inhibition of topoisomerase II by benzene and its metabolites leads to chromosomal alterations that may play a role in the development of leukemia. However, the repair studies reported here continue to represent an important area of interest even though the exact biological role of these benzene-DNA adducts is not yet understood. Further studies will be needed, especially in mammalian systems, to determine whether multiple mechanisms are to contribute to benzene-induced carcinogenesis, or which mechanism plays the more significant role.

In the present study, we have studied and compared the repair specificity toward $N^{2}-4-\mathrm{HOPh}-\mathrm{dG}$ of three E. coli repair mechanisms. By detecting the 5' incision, we revealed that this adduct is a novel substrate for E. coli UvrABC nuclease. Although NER is known to be the major mechanism for repair of a wide spectrum of genotoxic DNA adducts, especially bulky ones such as PAH- and enal-induced DNA adducts, there has been no direct evidence on its involvement in processing of specific 
benzene-derived covalent adducts. Using the supF forward mutation assay, Gaskell et al (Gaskell et al., 2005) demonstrated that when $p$-BQ-treated plasmids were transfected into human NER-deficient XPA cells, an overall higher mutation frequency at guanine residues occurred compared with the NER-proficient cells, suggesting repair of $p$-BQ-induced $d G$ adducts by NER. Using UvrABC as a model system, our data on UvrABC-mediated incision of $p$-BQ-modified plasmid DNA further support a role of NER in protection against benzene-induced DNA damage. Moreover, using defined oligonucleotide substrate, this work provides, for the first time, distinctive biochemical evidence on NER of a specific benzene-DNA adduct, i.e., $N^{2}-4-\mathrm{HOPh}-\mathrm{dG}$. Further investigation will be undertaken to examine the excision repair of this adduct in mammalian cells. It should also be pointed out that it is still not known whether the exocyclic benzetheno adducts, which are larger in size than $N^{2}-4-\mathrm{HOPh}-\mathrm{dG}$, are repaired by the NER pathway, in addition to their AP endonuclease-mediated repair. In Fig. 2, the $p$-BQ-induced lesions in plasmid DNA that were incised by UvrABC may likely include those other than $N^{2}-4-\mathrm{HOPh}-\mathrm{dG}$, for instance, the benzetheno bases.

The UvrABC activity found for $N^{2}-4-\mathrm{HOPh}-\mathrm{dG}$ has another important implication, that is, enabling one to use the UvrABC/ligation-mediated PCR (UvrABC/LMPCR) approach (Denissenko et al., 1996; Feng et al., 2006) to detect and quantify the formation of this adduct in critical cellular genes at nucleotide resolution.

In our data, the lack of repair of $N^{2}-4-\mathrm{HOPh}-\mathrm{dG}$ by damage-specific AP endonucleases and DNA glycosylases suggests that the structural features of this 
adduct and/or local DNA conformation do not support recognition by these enzymes. We previously discovered that $E$. coli Exo III and Endo IV and human APE1 are able to recognize and incise oligonucleotides containing a benzetheno adduct of $\mathrm{dA}, \mathrm{dC}$ or dG (Chenna et al., 1995; Hang et al., 1996; Hang et al., 1998). To understand the structural basis for such specificity, we also studied the conformation of adducted DNA duplexes using MD simulations (Guliaev et al., 2004; Xie et al., 2005) which showed that the benzetheno adducts do not pair with the opposite base and cannot be easily accommodated into DNA duplexes due to their unusually large van der Waals surface. There is either a significant displacement of the adduct toward the major groove (for both $\mathrm{A}$ and $\mathrm{C}$ adducts), or the opposite base has to rotate out of the duplex (for $\mathrm{G}$ adduct), leading to an extrahelical conformation. Many previous structural studies suggest that DNA glycosylases and AP endonucleases, including Exo III and Endo IV, use a flip-out mechanism for base excision or nucleotide incision that flip the modified base out of the DNA groove (Friedberg et al., 2005). It has been shown that disruption of or compromised base pairing at a damage site could aid in flipping out the damaged base by human alkyladenine-DNA glycosylase (AAG), thus affecting specificity and enzymatic efficiency (O'Brien and Ellenberger, 2004). Therefore, based on our biochemical and MD simulation results, it is reasonable to suggest that $N^{2}-4-\mathrm{HOPh}-\mathrm{G}$, which forms both stable base pairing with opposite C through three hydrogen bonds (Fig. 6) and more favorable stacking interactions with its neighboring bases than an unmodified $\mathrm{G}\left(\left(\sim 3 \mathrm{kcal} \mathrm{mol}^{-1}\right.\right.$ lower, see Fig. 7), is less susceptible to the flip-out mechanisms employed by the AP endonucleases or glycosylases tested, which may explain in part the inability of these enzymes to 
remove this adduct. In the case of UvrABC activity for $N^{2}-4-\mathrm{HOPh}-\mathrm{G}$, a mechanism for its specificity could be hypothesized based on the recently proposed functions of base flipping in UvrB/UvrC interactions with damaged DNA (Malta et al., 2006; Malta et al., 2008). In the latter studies Malta et al. showed that base flipping takes place upon UvrB binding to damaged DNA, which, however, appears not to involve the damaged base itself, but the neighboring/opposite bases, such as the base 3' adjacent to a damaged base. The conformational bases for this putative mechanism to occur in UvrABC recognition and processing of $N^{2}-4-\mathrm{HOPh}-\mathrm{G}$ are (1) the strong hydrogen bonding and stacking interactions observed for the adducted base; and (2) the lower stacking interactions for the neighboring bases of the adduct as compared to those of the adduct itself. Both could then facilitate base flipping that is thought to be important for UvrABC-mediated damage recognition and incision. 


\section{Acknowledgements}

This work was supported by the NIH R01 grant CA72079 (to B.H.) and was administrated by the Lawrence Berkeley National Laboratory under Department of Energy contract DE-AC02-05CH11231. Support was also provided by Center for Computing for Life Sciences Mini-grant, SFSU (to A.G.) and Minority Access to Research Careers National Institutes of Health Grant MBRS RISE R25-GM59298.

\section{Conflict of interest statement}

The authors declare that there are no conflicts of interest. 


\section{References}

Bauer, H., Dimitriadis, E.A., Snyder, R., 1989. An in vivo study of benzene metabolite DNA adduct formation in liver of male New Zealand rabbits. Arch Toxicol 63, 209213.

Bayly, C., Cieplak, P., Cornell, W., Kolman, P.A., 1993. A well-behaved electrostatic potential based method using charge restraints for deriving atomic charges:the RESP model. J Phys Chem 97, 10269-10280.

Bodell, W.J., Pathak, D.N., Levay, G., Ye, Q., Pongracz, K., 1996. Investigation of the DNA adducts formed in B6C3F1 mice treated with benzene: implications for molecular dosimetry. Environ Health Perspect 104 Suppl 6, 1189-1193.

Chenna, A., Gupta, R.C., Bonala, R.R., Johnson, F., Hang, B., 2008. Synthesis of the fully protected phosphoramidite of the benzene-DNA adduct, $\mathrm{N}^{2}$-(4Hydroxyphenyl)-2'-deoxyguanosine and incorporation of the later into DNA oligomers. Nucleosides Nucleotides Nucleic Acids 27, 979-991.

Chenna, A., Hang, B., Rydberg, B., Kim, E., Pongracz, K., Bodell, W.J., Singer, B., 1995. The benzene metabolite p-benzoquinone forms adducts with DNA bases that are excised by a repair activity from human cells that differs from an ethenoadenine glycosylase. Proc Natl Acad Sci U S A 92, 5890-5894.

Chenna, A., Singer, B., 1995. Large scale synthesis of p-benzoquinone-2'-deoxycytidine and p-benzoquinone-2'-deoxyadenosine adducts and their site-specific incorporation into DNA oligonucleotides. Chem Res Toxicol 8, 865-874. 
Chenna, A., Singer, B., 1997. Synthesis of a benzene metabolite adduct, 3"-hydroxy$1, \mathrm{~N}^{2}$-benzetheno-2'-deoxyguanosine, and its site-specific incorporation into DNA oligonucleotides. Chem Res Toxicol 10, 165-171.

Costantini, A.S., Gorini, G., Consonni, D., Miligi, L., Giovannetti, L., Quinn, M., 2009. Exposure to benzene and risk of breast cancer among shoe factory workers in Italy. tumori 95, 8-12.

Denissenko, M.F., Pao, A., Tang, M., Pfeifer, G.P., 1996. Preferential formation of benzo[a]pyrene adducts at lung cancer mutational hotspots in P53. Science 274, 430-432.

Feng, Z., Hu, W., Hu, Y., Tang, M.S., 2006. Acrolein is a major cigarette-related lung cancer agent: Preferential binding at p53 mutational hotspots and inhibition of DNA repair. Proc Natl Acad Sci U S A 103, 15404-15409.

Friedberg, E.C., Walker, G.C., Siede, W., Wood, R.D., Schultz, R.A., Ellenberger, T., 2005. DNA Repair and Mutagenesis. ASM Press, pp. 1164.

Gaskell, M., Jukes, R., Jones, D.J., Martin, E.A., Farmer, P.B., 2002. Identification and characterization of (3",4"-dihydroxy)-1, $\mathrm{N}^{2}$-benzetheno-2'-deoxyguanosine 3'monophosphate, a novel DNA adduct formed by benzene metabolites. Chem Res Toxicol 15, 1088-1095.

Gaskell, M., McLuckie, K.I., Farmer, P.B., 2004. Comparison of the mutagenic activity of the benzene metabolites, hydroquinone and para-benzoquinone in the supF forward mutation assay: a role for minor DNA adducts formed from hydroquinone in benzene mutagenicity. Mutat Res 554, 387-398. 
Gaskell, M., McLuckie, K.I., Farmer, P.B., 2005. Comparison of the repair of DNA damage induced by the benzene metabolites hydroquinone and p-benzoquinone: a role for hydroquinone in benzene genotoxicity. Carcinogenesis 26, 673-680.

Guliaev, A.B., Hang, B., Singer, B., 2002. Structural insights by molecular dynamics simulations into differential repair efficiency for ethano-A versus etheno-A adducts by the human alkylpurine-DNA N-glycosylase. Nucleic Acids Res 30, 3778-3787.

Guliaev, A.B., Hang, B., Singer, B., 2004. Structural insights by molecular dynamics simulations into specificity of the major human AP endonuclease toward the benzene-derived DNA adduct, pBQ-C. Nucleic Acids Res 32, 2844-2852.

Hang, B., 2004. Repair of exocyclic DNA adducts: rings of complexity. Bioessays 26, 1195-1208.

Hang, B., Chenna, A., Fraenkel-Conrat, H., Singer, B., 1996. An unusual mechanism for the major human apurinic/apyrimidinic (AP) endonuclease involving 5 ' cleavage of DNA containing a benzene-derived exocyclic adduct in the absence of an AP site. Proc Natl Acad Sci U S A 93, 13737-13741.

Hang, B., Chenna, A., Sagi, J., Singer, B., 1998. Differential cleavage of oligonucleotides containing the benzene-derived adduct, $1, \mathrm{~N}^{6}$-benzetheno-dA, by the major human AP endonuclease HAP1 and Escherichia coli exonuclease III and endonuclease IV. Carcinogenesis 19, 1339-1343.

Hang, B., Downing, G., Guliaev, A.B., Singer, B., 2002. Novel activity of Escherichia coli mismatch uracil-DNA glycosylase (Mug) excising 8-(hydroxymethyl)-3, $\mathrm{N}^{4}$ ethenocytosine, a potential product resulting from glycidaldehyde reaction. Biochemistry 41, 2158-2165. 
Hang, B., Rothwell, D.G., Sagi, J., Hickson, I.D., Singer, B., 1997. Evidence for a common active site for cleavage of an AP site and the benzene-derived exocyclic adduct, $3, \mathrm{~N}^{4}$-benzetheno-dC, in the major human AP endonuclease. Biochemistry $36,15411-15418$.

Hansen, J., 2000. Elevated risk for male breast cancer after occupational exposure to gasoline and vehicular combustion products. Am J Ind Med 37, 349-352.

Huff, J.E., Haseman, J.K., DeMarini, D.M., Eustis, S., Maronpot, R.R., Peters, A.C., Persing, R.L., Chrisp, C.E., Jacobs, A.C., 1989. Multiple-site carcinogenicity of benzene in Fischer 344 rats and B6C3F1 mice. Environ Health Perspect 82, 125 163.

IARC, 1982. IARC monographs on the evaluation of the carcinogenic risk of chemicals to humans. Some industrial chemicals and dyestuffs. International Agency for Research on Cancer, Lyon, France.

Ischenko, A.A., Saparbaev, M.K., 2002. Alternative nucleotide incision repair pathway for oxidative DNA damage. Nature 415, 183-187.

Jowa, L., Winkle, S., Kalf, G., Witz, G., Snyder, R., 1986. Deoxyguanosine adducts formed from benzoquinone and hydroquinone. Adv Exp Med Biol 197, 825-832.

Levay, G., Pongracz, K., Bodell, W.J., 1991. Detection of DNA adducts in HL-60 cells treated with hydroquinone and p-benzoquinone by ${ }^{32} \mathrm{P}$-postlabeling. Carcinogenesis $12,1181-1186$.

Malta, E., Moolenaar, G.F., Goosen, N., 2006. Base flipping in nucleotide excision repair. J Biol Chem 281, 2184-2194. 
Malta, E., Verhagen, C.P., Moolenaar, G.F., Filippov, D.V., van der Marel, G.A., Goosen, N., 2008. Functions of base flipping in E. coli nucleotide excision repair. DNA Repair (Amst) 7, 1647-1658.

McDonald, T.A., Holland, N.T., Skibola, C., Duramad, P., Smith, M.T., 2001. Hypothesis: phenol and hydroquinone derived mainly from diet and gastrointestinal flora activity are causal factors in leukemia. Leukemia 15, 10-20.

Moolenaar, G.F., Bazuine, M., van Knippenberg, I.C., Visse, R., Goosen, N., 1998. Characterization of the Escherichia coli damage-independent UvrBC endonuclease activity. J Biol Chem 273, 34896-34903.

Nakayama, A., Noguchi, Y., Mori, T., Morisawa, S., Yagi, T., 2004. Comparison of mutagenic potentials and mutation spectra of benzene metabolites using supF shuttle vectors in human cells. Mutagenesis 19, 91-97.

NTP, 2005. 11th Report on carcinogens. U.S. Department of Health and Human Services, National Toxicology Program, Atlanta, GA.

O'Brien, P.J., Ellenberger, T., 2004. Dissecting the broad substrate specificity of human 3-methyladenine-DNA glycosylase. J Biol Chem 279, 9750-9757.

Petralia, S.A., Vena, J.E., Freudenheim, J.L., Dosemeci, M., Michalek, A., Goldberg, M.S., Brasure, J., Graham, S., 1999. Risk of premenopausal breast cancer in association with occupational exposure to polycyclic aromatic hydrocarbons and benzene. Scand J Work Environ Health 25, 215-221.

Pigache, A., Cieplak, P., Dupradeau, F.-Y., 2004. Automatic and highly reproducible RESP and ESP charge derivation: Application to the development of programs 
RED and X RED. 27th ACS National Meeting, Anaheim, CA, USA March 28 April 1.

Pongracz, K., Bodell, W.J., 1991. Detection of 3'-hydroxy-1,N6-benzetheno-2'deoxyadenosine $3^{\prime}$-phosphate by ${ }^{32} \mathrm{P}$ postlabeling of DNA reacted with $\mathrm{p}$ benzoquinone. Chem Res Toxicol 4, 199-202.

Pongracz, K., Bodell, W.J., 1996. Synthesis of N²-(4-hydroxyphenyl)-2'-deoxyguanosine 3'-phosphate: comparison by 32P-postlabeling with the DNA adduct formed in HL60 cells treated with hydroquinone. Chem Res Toxicol 9, 593-598.

Pongracz, K., Kaur, S., Burlingame, A.L., Bodell, W.J., 1990. Detection of (3'-hydroxy)3, $\mathrm{N}^{4}$-benzetheno-2'-deoxycytidine-3'-phosphate by ${ }^{32} \mathrm{P}$-postlabeling of DNA reacted with p-benzoquinone. Carcinogenesis 11, 1469-1472.

Reardon, J.T., Sancar, A., 2005. Nucleotide excision repair. Prog Nucleic Acid Res Mol Biol 79, 183-235.

Rothwell, D.G., Hang, B., Gorman, M.A., Freemont, P.S., Singer, B., Hickson, I.D., 2000. Substitution of Asp-210 in HAP1 (APE/Ref-1) eliminates endonuclease activity but stabilises substrate binding. Nucleic Acids Res 28, 2207-2213.

Schmidt, M.W., Baldridge, K.K., Boatz, J.A., Elbert, S.T., Gordon, M.S., Jensen, J.H., Koseki, S., Matsunaga, N., Nguyen, K.A., Su, S., Windus, T.L., Dupuis, M., Montgomery, J.A., 1993. General Atomic and Molecular Electronic Structure System. JComputChem 14, 1347-1363.

Singer, B., Hang, B., 1997. What structural features determine repair enzyme specificity and mechanism in chemically modified DNA? Chem Res Toxicol 10, 713-732. 
Sorahan, T., Kinlen, L.J., Doll, R., 2005. Cancer risks in a historical UK cohort of benzene exposed workers. Occup Environ Med 62, 231-236.

Wallace, L., 1996. Environmental exposure to benzene: an update. Environ Health Perspect 104 Suppl 6, 1129-1136.

Whysner, J., Reddy, M.V., Ross, P.M., Mohan, M., Lax, E.A., 2004. Genotoxicity of benzene and its metabolites. Mutat Res 566, 99-130.

Xie, Z., Zhang, Y., Guliaev, A.B., Shen, H., Hang, B., Singer, B., Wang, Z., 2005. The pbenzoquinone DNA adducts derived from benzene are highly mutagenic. DNA Repair (Amst) 4, 1399-1409.

Yin, S.N., Hayes, R.B., Linet, M.S., Li, G.L., Dosemeci, M., Travis, L.B., Zhang, Z.N., Li, D.G., Chow, W.H., Wacholder, S., Blot, W.J., 1996. An expanded cohort study of cancer among benzene-exposed workers in China. Benzene Study Group. Environ Health Perspect 104 Suppl 6, 1339-1341.

Zou, Y., Shell, S.M., Utzat, C.D., Luo, C., Yang, Z., Geacintov, N.E., Basu, A.K., 2003. Effects of DNA adduct structure and sequence context on strand opening of repair intermediates and incision by UvrABC nuclease. Biochemistry 42, 12654-12661. 


\section{Tables}

Table 1. Hydrogen bonding values for $N^{2}-4-\mathrm{HOPh}-\mathrm{G}_{7}: \mathrm{C}_{44}$ pair calculated based on a $10 \mathrm{MD}$ trajectory.

\section{Figure legends}

Figure 1. Chemical structure of $N^{2}$-(4-hydroxyphenyl)-2'-deoxyguanosine $\left(N^{2}-4-\mathrm{HOPh}-\mathrm{dG}\right)$.

Figure 2. UvrABC incision of the plasmid DNA treated with $20 \mathrm{mM}$-BQ. Both the unmodified and modified pCMV plasmid ( $0.75 \mu \mathrm{g}$ per sample) were incubated with increasing amounts of UvrABC (1x: $1.4 \mathrm{nM} \mathrm{UvrA}, 1.4 \mathrm{nM} \mathrm{UvrB}$, and $1 \mathrm{nM} \mathrm{UvrC})$ at $30^{\circ} \mathrm{C}$ for $1 \mathrm{hr}$. Lanes 1 and 5 contained buffer only. The reactions were electrophoresed on $1 \%$ agarose gel with ethidium bromide.

Figure 3. UvrABC incision of the 40-mer substrate containing $N^{2}-4-\mathrm{HOPh}-\mathrm{dG}$.

Oligonucleotide sequences used in this study are shown on the top, including both the 40mer containing the adduct $(\mathrm{X})$ at position $20^{\text {th }}$ (from the $5^{\prime}$-end) and three oligonucleotide markers with different sizes. The gel image shows the detection of UvrABC incision of the oligonucleotide on the 5' side of the adduct. UvrABC (140 nM UvrA, $140 \mathrm{nM}$ UvrB and $100 \mathrm{nM} \mathrm{UvrC}$ ) was incubated with $20 \mathrm{fmol}$ of 5' end-labeled unmodified (lane 2) and adduct-containing 40-mer (lane 4) in an UvrABC buffer (see 2.2. Incision assays) at $37^{\circ} \mathrm{C}$ for $1 \mathrm{hr}$. The $5^{\prime}$ incision sites are indicated by the mobility of the co-running size markers.

Figure 4. Kinetic studies of UvrABC incision of the 40-mer containing $N^{2}-4-\mathrm{HOPh}-\mathrm{dG}$. The right graph shows the rate of $\mathrm{UvrABC}$ incision as a function of reaction time. 
UvrABC (140 nM UvrA, $140 \mathrm{nM} \mathrm{UvrB} \mathrm{and} 100 \mathrm{nM}$ UvrC) was incubated with $20 \mathrm{fmol}$ of 5' end-labeled adduct-containing 40-mer (all lanes) for the time points indicated. All of the four 5' incision bands detected in the left gel image were scanned and calculated as incision products. Lane 7 contained the 12-mer marker which indicates the major and first 5 ' incision band.

Figure 5. Determination of potential DNA glycosylase activity toward $N^{2}-4-\mathrm{HOPh}-\mathrm{G}$. The

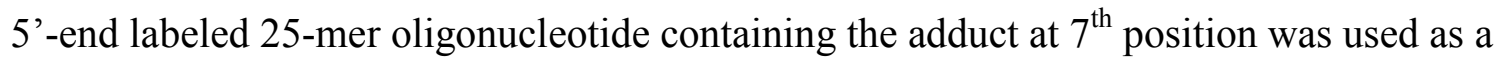
substrate. The incubation time was $1 \mathrm{hr}$ at $37^{\circ} \mathrm{C}$ for all the $E$. coli glycosylases tested. There was no detectable product(s) observed at the expected cleavage site (arrow) by these enzymes under the reaction conditions used.

Figure 6. Top (A) and side (looking at the minor groove) (B) views of the 3 base pair motifs containing G:C and $N^{2}-4-\mathrm{HOPh}-\mathrm{G}: \mathrm{C}$ pairs $\left(\mathrm{A}_{6}-\mathrm{G}_{7}-\mathrm{C}_{8} / \mathrm{T}_{45}-\mathrm{C}_{44}-\mathrm{G}_{43}\right.$ and $\mathrm{A}_{6}-N^{2}-4-\mathrm{HOPh}-\mathrm{G}_{7^{-}}$ $\left.\mathrm{C}_{8} / \mathrm{T}_{45}-\mathrm{C}_{44}-\mathrm{G}_{43}\right)$. The structures shown are the trajectory-averaged structures for the last $9 \mathrm{~ns}$ of the MD simulations. Hydrogen bonds are shown in yellow and G:C and $N^{2}-4-\mathrm{HOPh}-\mathrm{G}: \mathrm{C}$ pairs are colored by atoms.

Figure 7. Population distribution of the van der Waals interaction energies between adjacent bases at the adduct site $\mathrm{A}_{6}-N^{2}-4-\mathrm{HOPh}-\mathrm{G}_{7}-\mathrm{C}_{8}$ and corresponding bases $\mathrm{A}_{6}-\mathrm{G}_{7}-\mathrm{C}_{8}$ in unmodified oligonucleotide. The bases are labeled mod and unmod, respectively. The lower van der Waals interactions indicate lower perturbation in the stacking interactions. The $N^{2}-4-\mathrm{HOPh}-\mathrm{G}_{7}$ (blue) has a tendency to generate more stable stacking in B-DNA than a normal guanine $\mathrm{G}_{7}$ in unmodified duplex (red). The analysis includes 4800 structures from a 12.5 ns trajectory. 
Table 1. Hydrogen bonding values for $N^{2}-4-\mathrm{HOPh}-\mathrm{G}_{7}: \mathrm{C}_{44}$ pair calculated based on a $10 \mathrm{~ns}$ MD trajectory.

\begin{tabular}{|c|c|c|c|c|}
\hline \multirow{2}{*}{ H-bond } & H-bond & $\%$ & Average Distance & Average Angle \\
& Acceptor & Occupied & $(\AA)$ & $\left({ }^{\mathbf{a}}\right)$ \\
\hline $4-\mathrm{HOPh}-\mathrm{G}_{7} \mathrm{~N} 2$ & $\mathrm{C}_{44} \mathrm{O} 2$ & 95.30 & $2.915 \pm 0.14$ & $16.62 \pm 9.54$ \\
\hline $4-\mathrm{HOPhG}_{7} \mathrm{~N} 1$ & $\mathrm{C}_{44} \mathrm{~N} 3$ & 95.50 & $2.987 \pm 0.11$ & $17.46 \pm 8.70$ \\
& & & & \\
\hline $\mathrm{C}_{44} \mathrm{~N} 4$ & $4-\mathrm{HOPh}-\mathrm{G}_{7} \mathrm{O} 6$ & 94.30 & $2.898 \pm 0.14$ & $16.41 \pm 9.29$ \\
& & & & \\
\hline
\end{tabular}

The percent occupancy was calculated based on a heavy atom-heavy atom distance cutoff of $\leq 3.3 \AA$ and a heavy atom-hydrogen-heavy atom angle of $\leq 130^{\circ}$. 


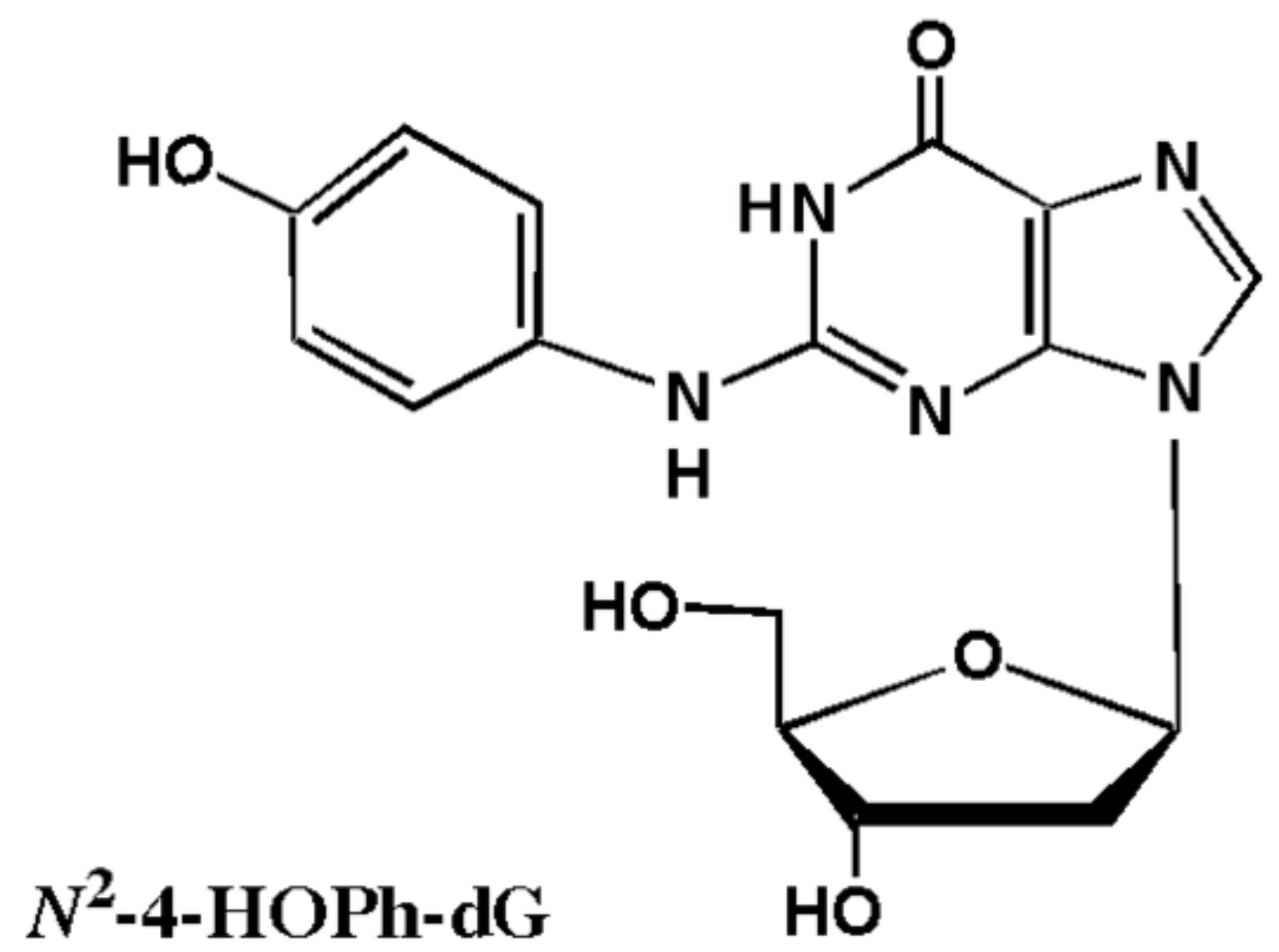



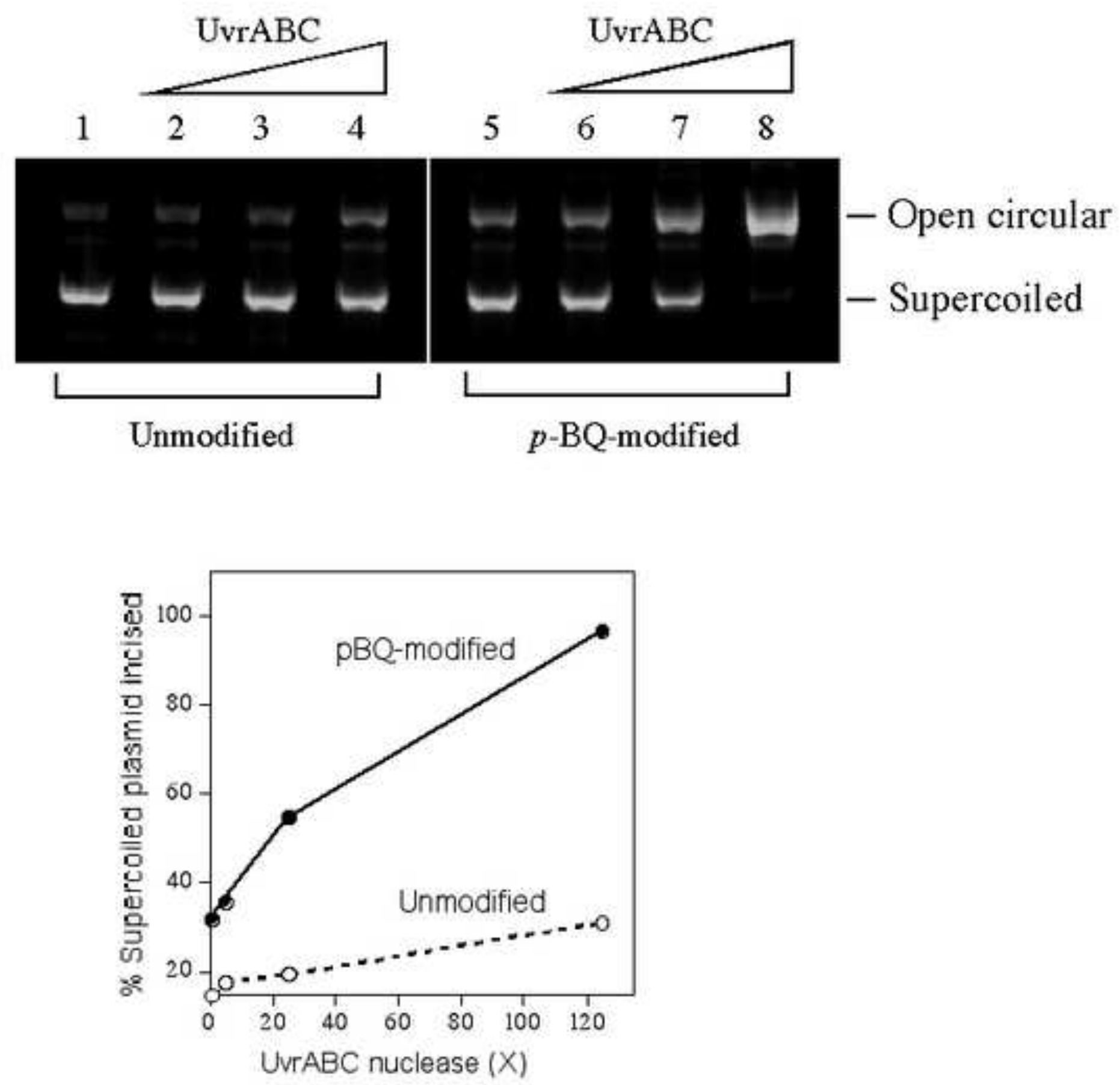
5'-TTGCTTTGTCACCCAGGCTXGACTGCAGTGGTACAATCAT (40-mer)

5-TTGCTTTGTCACCCAGGCT (19-mer)

5'-TTGCTTTGTCAC (12-mer)

5-TTGCTTT (7-mer)

$\mathrm{X}=N^{2}-4-$ HOPh-dG

UvrABC -+++
4-HOPh-dG --++

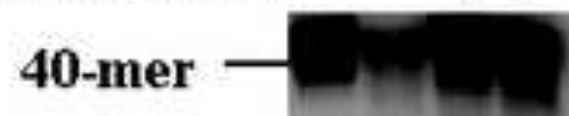

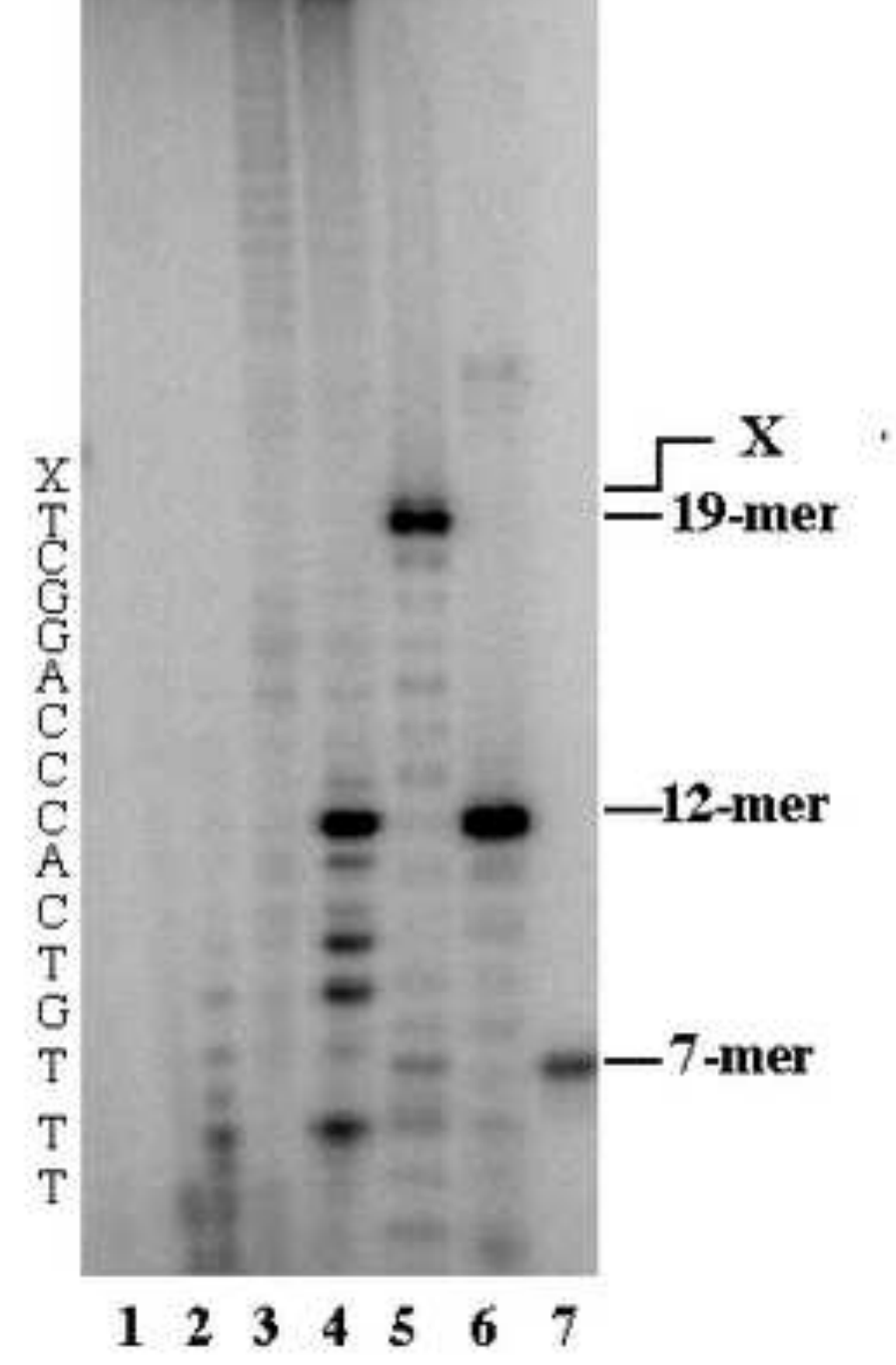


Time (min) $\quad \begin{array}{llllll}0 & 1 & 5 & 15 & 30 & 60\end{array}$

UvrABC ++++++

\section{4-HOPh-dG-} 40-mer

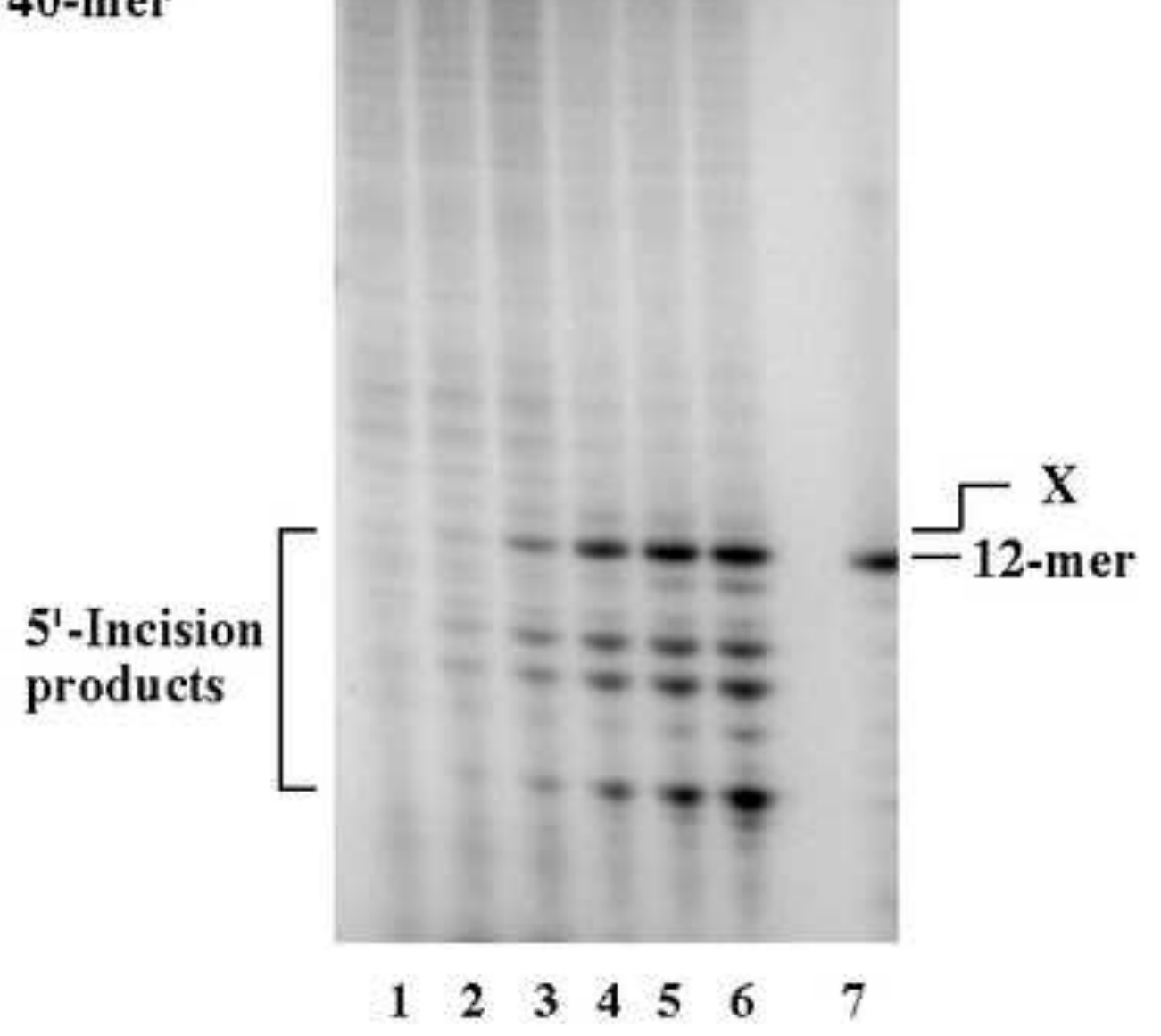

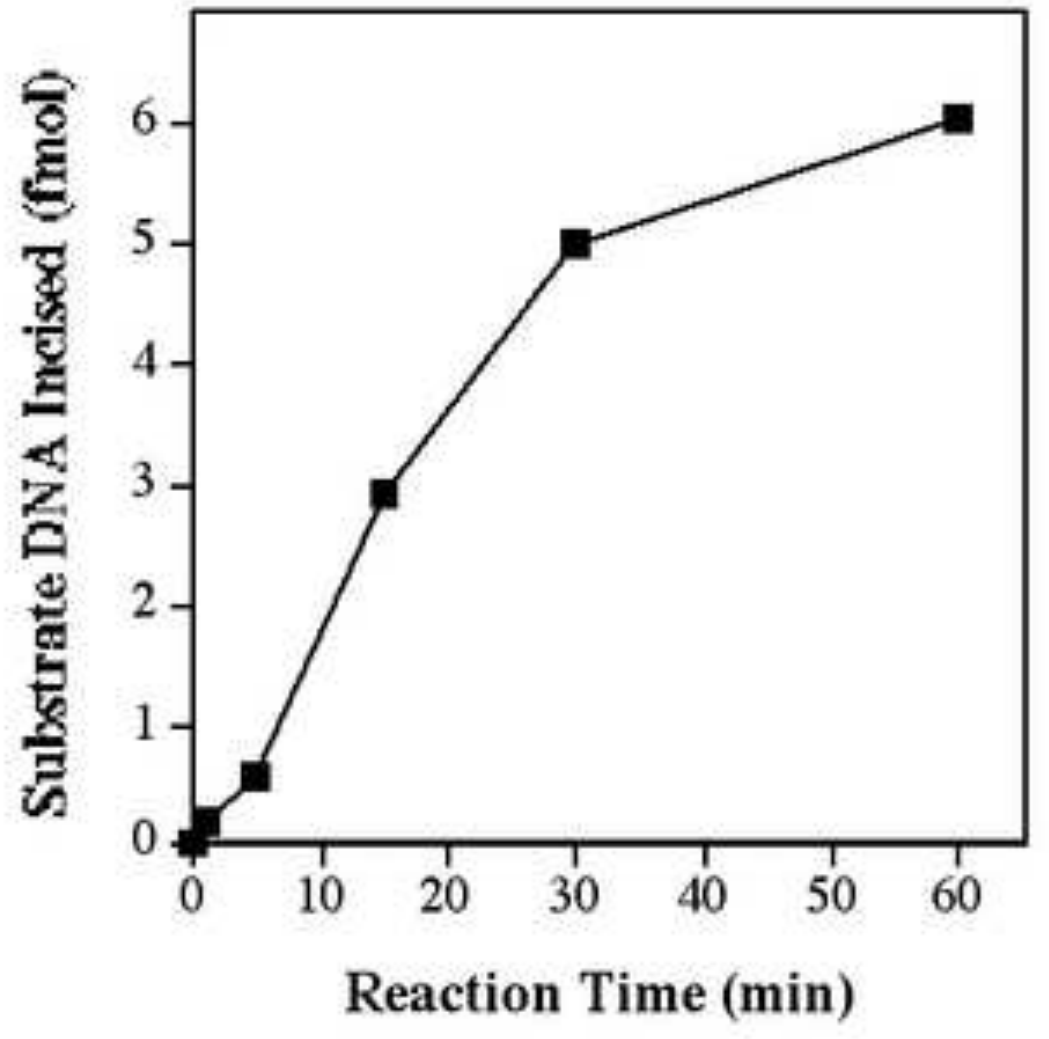


Figure 5
Click here to download high resolution image

5'-CCGCTAXCGGGTACCGAGCTCGAAT

$$
\mathrm{X}=N^{2}-4-\mathrm{HOPh}-\mathrm{dG}
$$

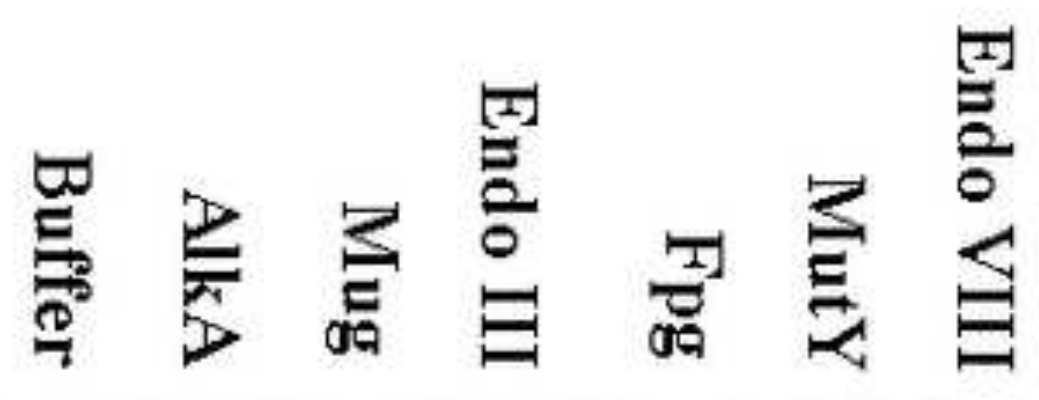

\section{5-mer}

\section{Cleavage}

\section{site}

$$
\begin{array}{lllllll}
1 & 2 & 3 & 4 & 5 & 6 & 7
\end{array}
$$


Click here to download high resolution image
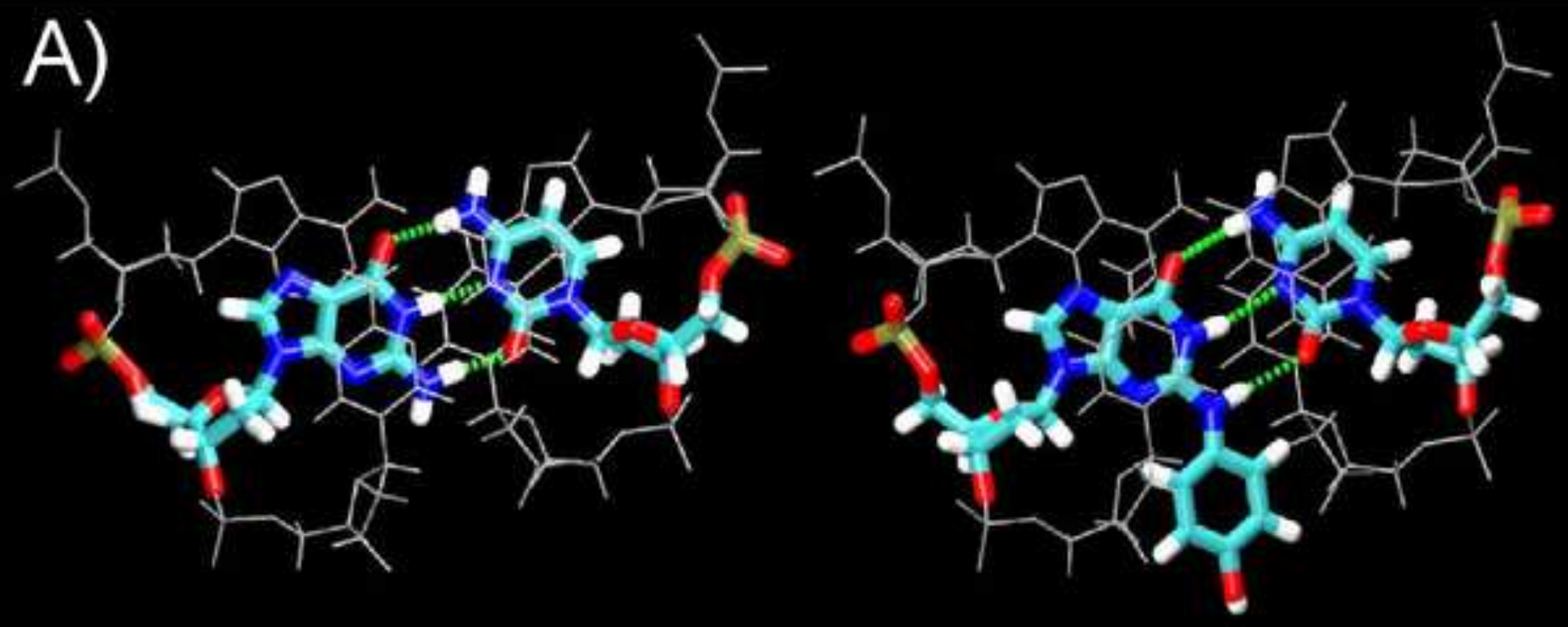

B)
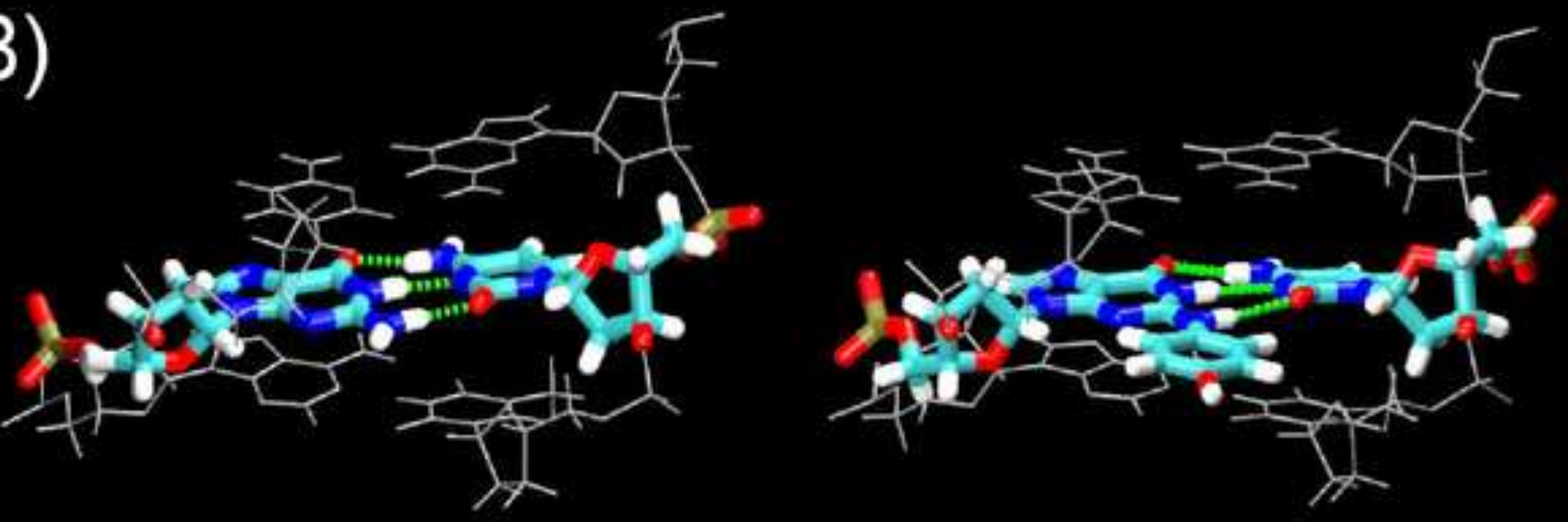

$\mathrm{G}: \mathrm{C}$

$N^{2}-4-H O P h-G: C$ 


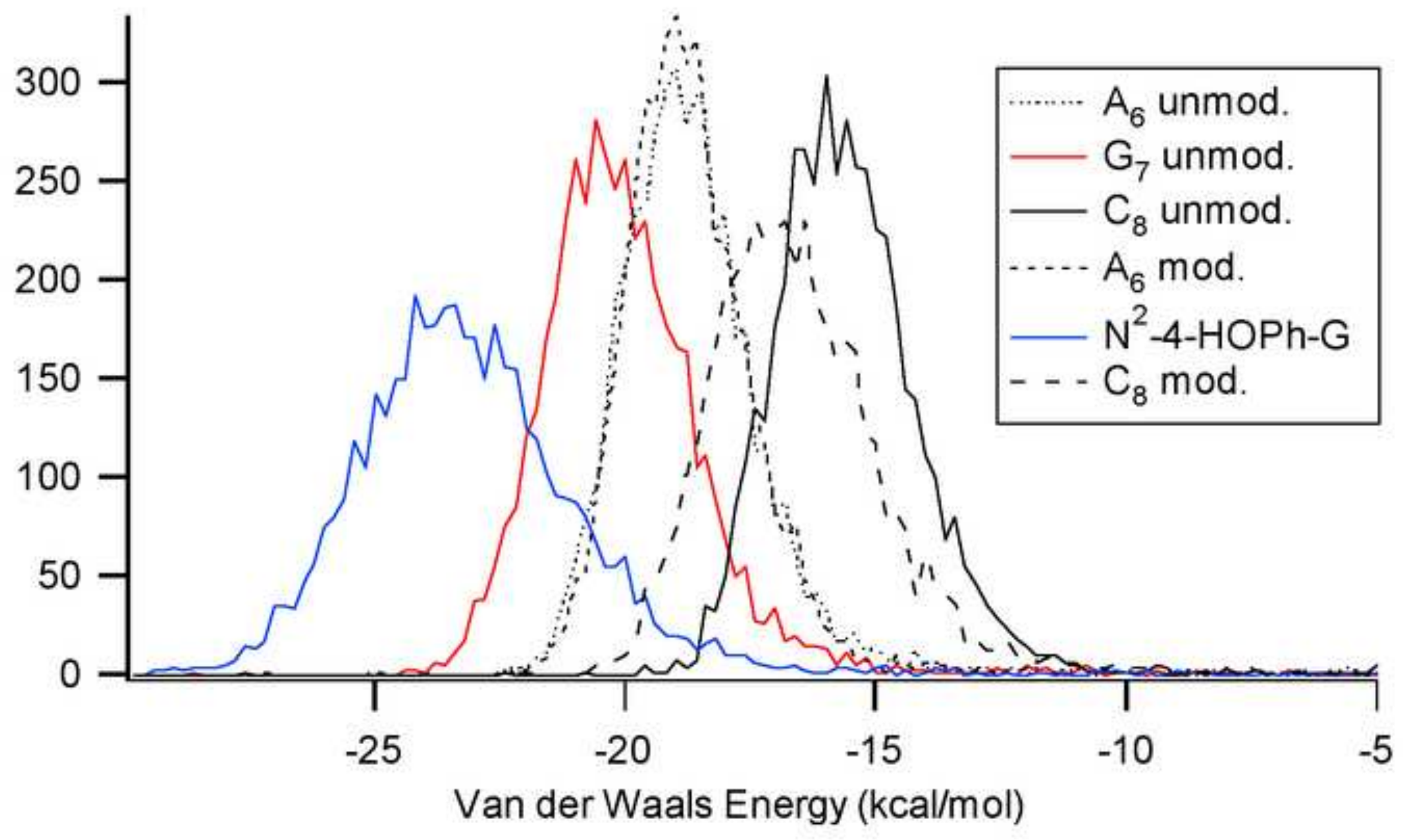




\section{Toxicology Letters}

Conflict of Interest Policy

Article Title: Benzene-derived $N^{2}-(4-$

hydroxyphenyl)-deoxyguanosine adduct:

UvrABC incision and its conformation in DNA

Author name:

Bo Hang

\section{Declarations}

Toxicology Letters requires that all authors sign a declaration of conflicting interests. If you have nothing to declare in any of these categories then this should be stated.

Conflict of Interest and Source of Funding

A conflict of interest exists when an author or the author's institution has a financial or other relationship with other people or organizations that may inappropriately influence the author's actions. All submissions to Toxicology Letters must include disclosure of all relationships that could be viewed as presenting a potential conflict of interest. Toxicology Letters may use such information as a basis for editorial decisions and may publish such disclosures if they are believed to be important to readers in judging the article.

Conflict of Interest Statement for Authors

All authors must disclose any financial, personal, or their relationships with other people or organizations within 3 years of beginning the work submitted that could inappropriately influence the work submitted. Examples of conflicts include employment, consultancies, stock ownership, honoraria, paid expert testimony, patent applications/registrations, and grants. If there are no conflicts of interest, authors should state that there are none in the box below. Investigators should disclose potential conflicts to participants in clinical trials and other studies and should state in the manuscript whether they have done so. Toxicology Letters may decide not to publish on the basis of a declared conflict, such as the financial interest of an author in a company (or its competitors) that makes a product discussed in the paper.

\section{Please state any competing interests}

The author declares that there are no conflicts of interest.

\section{Role of Funding Source}

All sources of funding should be declared in the box below. Authors must also describe the role of the study sponsor(s), if any, in a study design; in the collection, analysis, and interpretation of data; in the writing of the report; and in the decision to submit the paper for publication. If the study sponsor(s) had no such involvement, the authors should so state.

Please state any sources of funding for your research

NIH/NCI R01 grant CA72079 to B.H.

Signature (a scanned signature is acceptable, but each author must sign)

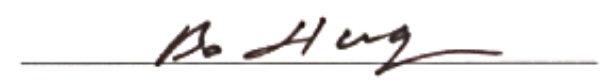

Print name

$$
\text { BO HANG }
$$




\section{Toxicology Letters}

\section{Conflict of Interest Policy}

Aricle Title: Benzene-derived $N^{2}-(4-$

hydroxyphenyl)-deoxyguanosine adduct:

U $\mathrm{vr} \wedge \mathrm{BC}$ incision and its conformation in DNA
Author n:ume:

Anton B. Guliacv

\section{Declarations}

Toxicology Letters requires that all authors sign a declaration of conflicting interests. If you fisve nothing to declare in any of these categories then this should be stated.

\section{Conflict of Interest and Source of Funding}

A conflict of interest exists when an author or the author's institution has a financial or other relations hip with other people or organizations that may inappropriately influence the author's actions. All submissions to Toxicology Letters must include disclosure of all relationships that oould be viewec as presenting a potential conflict of interest. Toxicology Letters may use such information as a basi's for editorial decisions and may publish such disclosures if they are belleved to be important to readers in judging the article.

\section{Conflict of Interest Statement for Authors}

All authors must disclose any financial, personal, or their relationships with other people or organizajions within 3 years of beginning the work submitted that could inappropriately influence the work submitied. Examples of conflicts include employment, consultancies, stock ownership, honoraria, paid exizert testimony, patent applications/registrations, and grants. If there are no conflicts of interest, authors should state that there are none in the box below. Investigators should disclose potential conflict; to participants in ellinical trials and other studles and should state in the manuscript whether they have done so. Toxicology Letters may decide not to publish on the basis of a declared conflict. such as the financial interest of an author in a company (or Its competitors) that makes a product discussed in the paper.

\section{Please state any competing interests}

The author declares that there arc no conflicts of intercst.

Role of Funding Source

All sources of funding should be declared in the box below. Authors must also describe the role of this study sponsor(s), if any, in a study design; in the collection, analysis, and interpretation of data: in th: writing of the report; and in the declsion to submit the paper for publication. If the study sponsor(s) had no such involvement, the authors should so state.

\section{Please state any sources of funding for your research}

Start-up grant from SFSU io A.C.

SFSU. Center for Computing for 1,ife Sciences Mini-grant to A.C.

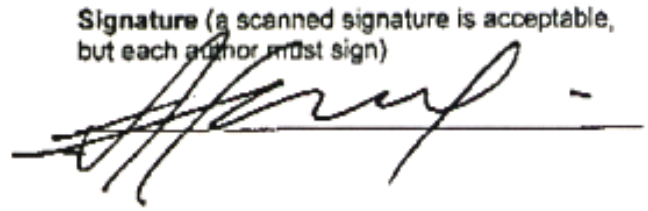

Print name

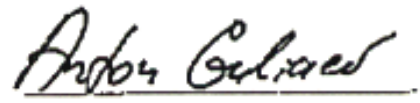




\section{Toxicology Letters \\ Conflict of Interest Policy}

Artick lin: Benzene-derived $N^{2}-(4-$

hydroxyphenyl)-deoxyguanosine adduct:

UvrABC incision and its conformation in DNA
Autron name:

Ahmed Chenna

\section{Declarations}

Toxicology Letters requires that all authors sign a declaration of conflicting interests. If you have nothing to declare in any of these categories then this should be stated.

\section{Conflict of Interest and Source of Funding}

A conflict of interest exists when an author or the author's institution has a financial or other relationship with other people or organizations that may inappropriately influence the author's actions. All submissions to Toxicology Letters must include disclosure of all relationships that could be viewed as presenting a potential conflict of interest. Toxicology Letters may use such information as a basis for editorial decisions and may publish such disclosures if they are believed to be important to readers in judging the article.

\section{Conflict of Interest Statement for Authors}

All authors must disclose any financial, personal, or their relationships with other people or organizations within 3 years of beginning the work submitted that could inappropriately influence the work submitted. Examples of conflicts include employment, consultancies, stock ownership, honoraria, paid expert testimony, patent applications/registrations, and grants. If there are no conflicts of interest, authors should state that there are none in the box below. Investigators should disclose potential conflicts to participants in clinical trials and other studies and should state in the manuscript whether they have done so. Toxicology Letters may decide not to publish on the basis of a declared conflict, such as the financial interest of an author in a company (or its competitors) that makes a product discussed in the paper.

\section{Please state any competing interests}

The author declares that there are no conflicts of interest.

Role of Funding Source

All sources of funding should be declared in the box below. Authors must also describe the role of the study sponsor(s), if any, in a study design; in the collection, analysis, and interpretation of data; in the writing of the report; and in the decision to submit the paper for publication. If the study sponsor(s) had no such involvement, the authors should so state.

Please state any sources of funding for your research

No funding sources were involved.

Signature (a scanned signature is acceptable, but each author must sign)

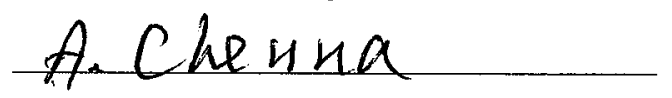

Print name

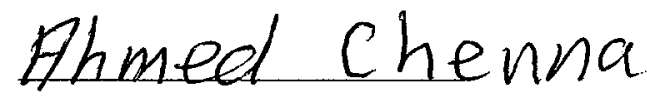




\section{Toxicology Letters}

\section{Conflict of Interest Policy}

Aricle litle: Benzene-derived $N^{2}-(4-$

hydroxyphenyl)-deoxyguanosine adduct:

UvrABC incision and its conformation in DNA

Auther nanse:

Ben Rodriguez

\section{Declarations}

Toxicology Letters requires that all authors sign a declaration of conflicting interests. If you have nothing to declare in any of these categorles then this should be stated.

Conflict of Interest and Source of Funding

A conflict of interest exlsts when an author or the author's institution has a financial or other relationship with other people or organizations that may inapproprlately influence the author's actions. All submissions to Toxicology Letters must include disclosure of all relationships that could be viewed as presenting a potential conflict of interest. Toxicology Letters may use such information as a basis tor editorlal decisions and may publish such disclosures if they are believed to be important to readers in judging the article.

\section{Conflict of Interest Statement for Authors}

All authors must disclose any financial, personal, or their relationships with othar people or organizaticns within 3 years of beginning the work submitted that could inappropriately influence the work submitsod. Examples of conflicts include employment, consultancies, stock ownership, honoraria, paid excert testimony, patent applications/registrations, and grants. If there are no conflicts of interest, authirs should state that there are none in the box below. Investigators should disclose potential conflicts to participants in clinical trials and other studies and should state in the manuscript whether they have done so. Toxicology Letters may decide not to publish on the basis of a declared conflict, such as he financial interest of an author in a company (or its competitors) that makes a product discussed in the paper.

\section{Please state any competing interests}

The author declares that there are no conflicts of interest.

\section{Role of Funding Source}

All sources of funding should be declared in the box below. Authors must also describe the role of the study sponsor( $\mathrm{s})$, if any, in a study design; in the collection, analysis, and interpratation of data; in the writing of the report; and in the decision to submit the paper for publication. If the study sponsor(s) had no such involvement, the authors should so state.

\section{Please state any sources of funding for your research}

Start-up grant from SFSU to $\Lambda . G$.

SFSU. Center for Computing for Life Sciences Mini-grant to A.G.

NIH MBRS-RISE fellowship to B.R.

Signature (a scanned siggature is accoptable.

but each authormet sigh

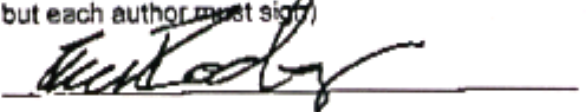

Print name

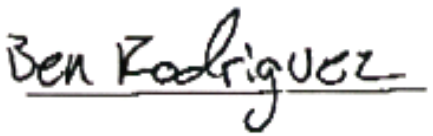




\section{Toxicology Letters}

\section{Confict of Interest Policy}

Articlt i ille: Benzene-derived $N^{2}-(4$.

hydroxyphenyl)-dcoxyguanosinc adduct:

UvrABC incision and its conformation in DNA
Authur name:

Yanu Yang

Taxicology Letters requires that all authors sign a declaration of conflicting interasts. If you have nothing to declare in any of these categories then this should be stated.

Conflict of Interest and Source of Funding

A conflict of interest exists when an author or the author's institution has a financial or other relation 1 ship with other people or organizations that may inappropriately influence the author's actior:s. All submissions to Toxicology Letters must include disclosure of all relationships that could be viewsid as presenting a potential conflict of interest. Toxicology Lotters may use such information as a basis for editorial decisions and may publish such disclosures if they are believed to be important to reachrs in judging the article.

\section{Conflict of Interest Statement for Authors}

All authors must disclose any financial, personal, or their relationships with other people or organizz tions within 3 years of beginning the work submitted that could inappropriately influence the work subrritted. Examples of conflicts include employment, consultancies, stock ownership, honoraria. paid axpert testimony, patent applications/registrations, and grants. If there are no conflicts of interest, authors should state that there are none in the box below. Investigators should disclose potential conflits to participants in clinical trials and other studies and should state in the manuscript whether they have done so. Toxicology Lelters may decide not to publish on the basis of a declared conflict, such is the financial interest of an author in a company (or its competitors) that makes a product discussed in the paper.

Please state any competing interests

The author declares that there are no conflicts of interest.

Role of Funding Source

All sources of funding should be declared in the box below. Authors must also describe the role of $y 1 e$ study sponsor(s), if any, in a study design; in the collection, analysis, and interpretation of data; In the writing of the report; and in the decision to submit the paper for publication. If the study sponsor(s) r ad no such involvement, the authors should so state.

\section{Please state any sources of funding for your research}

Start-up grant from SFSU to A.G.

SFSU. Center for Computing for Life Sciences Mini-grant to A.G.

NIH MBRS-RISE fellowship to Y. Y.

Signature (a scanned signature is acceptable. but each author must sign)

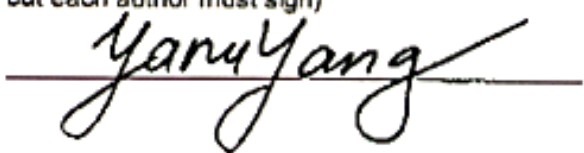

Print name

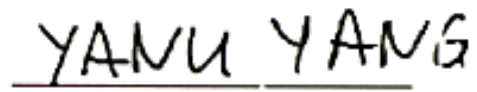

